\title{
Incorporating time-series into an interindustry analysis to model the regional economic structure: a case study of the Illawarra
}

\author{
Ashkan Masouman ${ }^{a^{*}}$ \\ Charles Harvie ${ }^{b}$
}

\begin{abstract}
Since the pioneering work of Glickman on embedding an input-output (IO) module into an econometric framework, ${ }^{1}$ there has been a plethora of studies on combining an IO analysis with an econometric model in the literature. The popularity of the combined framework is due to its superior performance in economic forecasting and higher accuracy in impact analysis. There are a number of approaches through which an IO model is combined with an econometric model. This paper examines three approaches to combine IO analysis with econometric modelling, namely embedded, coupled, and linked. All three approaches are applied to the Illawarra economy in a series of ex-post forecasting experiments. Each approach is applied to a hypothetical scenario of sectoral reallocation of government expenditure, to investigate certain key sectors that provide more jobs per dollar of expenditure relative to the other sectors. The comparative forecasting performance and impact analysis accuracy of each approach is examined.
\end{abstract}

Key words: Input-output analysis; Econometric modelling; Regional analysis, Integrated framework.

\section{Introduction}

One of the continuing attributes of regional science since its inception some 60 years ago has been on the development of tools for policy analysis. A significant emphasis has been placed on regional socioeconomic models, which covers the topic of regional analysis. The objective of this paper is to highlight the major contributions in the field of regional analysis. This paper focuses on one the most recent modelling developments, the integration of regional IO modelling with regional econometric modelling. In the past three decades, integrated models have been investigated by a number of economists to gain the benefits of both intersectoral details of IO modelling and dynamics of econometric modelling. ${ }^{2-10} \mathrm{~A}$ thorough analysis of the studies in the literature reveals that there is an emerging consensus on the motivations for implementing integrated models into regional planning. It is a common credence among integrated modellers

\footnotetext{
a SMART Infrastructure Facility, University of Wollongong, Northfields Ave, Wollongong NSW 2522, Australia

${ }^{\mathrm{b}}$ School of Accounting, Economics \& Finance, University of Wollongong, Northfields Ave, Wollongong NSW 2522, Australia

*Corresponding author: Ashkan Masouman ashkan@uow.edu.au http://dx.doi.org/10.14453/isngi2013.proc.31
} 
that the traditional tools for regional analysis are inadequate to deal with the complexity of the issues that are of interest to regional analysts. ${ }^{3,11}$

To analyse the structure of a regional economy and to examine the potential impacts of policies on the future economy of a region, a regional analyst often applies two key methods (Other operational methods of regional analysis are computable general equilibrium (CGE), economic base analysis, shift-share analysis, linear programming, and cost-benefit analysis). The first method is IO modelling, through which the interactions between economic sectors are examined and the impacts of exogenous shocks on the economy are determined. ${ }^{10,12}$ The multipliers in IO modelling enable analysts to calculate the direct and indirect effects of any shifts among various economic sectors and to trace the impacts of intersectoral transactions within an economy. The other method is econometric modelling, through which the growth rate of each sector is forecasted and the effects of a policy on high growth rate industries are evaluated. Nonetheless, each model applied alone ensue some drawbacks. For instance, IO models lack the dynamics of econometric models whilst on the other hand econometric models do not provide a detailed snapshot of intersectoral interactions among economic sectors of a region. ${ }^{9,13,14,15}$ Given the two methods, applied alone in analysis, the question is if the results of evaluating the potential effects of a policy such as adjustment of overall rate of inflation or adjustment of relative prices of household expenditure commodities are highly accurate? Considering the limitations of each method in isolation, a positive answer to this question is highly doubtful.

West and Jackson ${ }^{10}$ argue that in the standalone IO modelling, an exogenous shock to the economy entails a reaction from final demand to intermediate and primary inputs. Nonetheless, if changes in tax levels impact government expenditure, there is no reaction from primary inputs to final demand. Therefore it is required to implement a dynamic structure to apply time series in order to capture exogenous shocks through time. This feature can be gained by merging an IO model with an econometric model to combine the good properties of both methods ${ }^{1}$.

An integrated EC-IO model combines the advantages of both types of modelling, which in turn leads to increased accuracy in forecasting and to improved capabilities in impact analysis for regional planning. A significant number of studies have focused on applying the integrated framework in several regions within the U.S.,

However, in the Australian context, except for West ${ }^{9,17}$, no studies have been found in the literature focusing on the integrated EC-IO model to conduct regional analysis. The lack of studies in the literature on regional analysis is especially noticeable on the Illawarra region, which is an important region within New South Wales economy. Due to the economic transitions, as a result of globalization, that have occurred in the Illawarra's economy, an integrated EC-IO analysis on the Illawarra could be a stepping stone to further research on other regions around the globe that are similarly in a transitional phase. This paper explores the potential arising through the application of integrated EC-IO modelling to the Illawarra, a region in transition, to analyse the intersectoral relatedness and forecast structural shifts in the economy. Three different approaches are applied to unite the IO analysis with the econometric model, namely, coupled, embedded and linked approaches. 


\section{The region}

Due to globalization and structural adjustments over the last five decades, regions have become paramount factors in development of national economies. A new global environment of floating exchange rates, financial deregulation and globalization of capital markets has taken place over the last half a century. Consequently, the developed nations have entered an increasingly intricate and competitive global economy and in turn, the impact of regional economies on national economies has become vital in forming the dichotomy between the successful and the unsuccessful national economies. ${ }^{18}$ Since four decades ago nearly all member states of organization for economic co-operation and development (OECD) have witnessed major economic and social shifts. These structural shifts indicate the fast pace of technological advancement, importance of knowledge sectors, capital market deregulation, and increased overseas trades. ${ }^{19}$ Old industrial regions such as the Illawarra and New Castle in Australia; Lille in France; Liverpool in the UK; and Cleveland, Detroit and Pittsburgh in the US have declined or witnessed structural economic shifts as a result of globalization. ${ }^{18}$ Regions such as the Illawarra in Australia and Waterloo, Ontario in Canada have adopted global learning skills and cross training labour characteristics and they heavily rely on skilled labour to adapt to the impact of globalization.

The importance of choosing the Illawarra as a region in this research is reflected in two paths. Firstly the Illawarra regional economy plays a key role in the context of the Australian economy, which is discussed in the following paragraph. Secondly, what adds to the significance of this study in terms of its pertinence to the global context is the application of the methodology in this paper to regions outside Australia, that have the characteristics similar to those of the Illawarra's. The emphasis on the Illawarra economy has shifted from heavy industry, steel manufacturing and mining to knowledge sectors and technological advancement, being regarded as city of innovation. This research is applicable to regions with demographics and economy size commensurate with the Illawarra, regions that have adapted to structural shifts in the past five decades as a result of globalisation and increased level of competition, and regions that are in a transitional process of economy as a result of structural shifts.

The Illawarra has contributed considerable resources to the economy of Australia as it has been a leading steel and coal exporter. It boasts the largest plant for steel production in the southern hemisphere. ${ }^{20}$ The Illawarra is nationally acclaimed for metal fabrication and engineering. It has been considered the centre of excellence in research and development ${ }^{20}$, playing an integral role in technological advancement. In addition, it is a globally renowned provider of tertiary education. ${ }^{20}$ According to the Australian Bureau of Statistics ${ }^{21-23}$, the Illawarra statistical division has an unemployment ratio of $6.7 \%$. With a population of 436,117 people this indicates that nearly 13,114 of the current labour force are unemployed. Since one of the main objectives of regional planning is to increase employment, gaining higher accuracy in regional economic analysis would be a stepping stone in addressing the unemployment issues.

\section{Comparison of the estimation results}

For the first experiment, the two integration approaches, namely the coupled and the holistic embedded, are applied to a dynamic ex-post scenario for forecasting both total and sectoral 
employment for the period of 2009-2010. The reason for exclusion of standalone IO and linked approach is that due the static nature of those two models, they are not made for forecasting. Each of the two approaches in this experiment is based on parameters estimated over the 19902009 sample period. The comparison is made on the basis of mean absolute percentage error (MAPE) for the predicted values of each variable over the last two years of the sample period.

The results of the forecast show that the holistic embedded approach performs better than the coupled approach in forecasting total employment. This is due to the even distribution of the estimated values across all sectors, which is the main property of the holistic embedded approach. As noted on Table 1, the MAPE of the holistic embedded approach is far less than that of the coupled and the number of sectors with the lowest MAPE is four times that that of the coupled.

In terms of sectoral employment forecast, the coupled approach clearly outperforms the holistic embedded. The MAPE for the coupled approach is half of that of the holistic embedded and the number of sectors with the lowest MAPE is twice that of the embedded. A likely justification for this is that in a more diversified economy it is critical to avail of intersectoral linkages in defining the employment demand equations. The coupled approach imposes an exhaustive set of intersectoral relations in each employment equation and an extensive series of final demand equations; it is more sector-specific in terms of forecasting.

Table 1. Coupled versus embedded: MAPE for total and sectoral employment forecasts

\begin{tabular}{|l|l|l|}
\hline \multicolumn{3}{|c|}{ Mean absolute percentage errors for total employment forecasts 2009-2010 } \\
\hline Integration approach & Coupled & Holistic Embedded \\
\hline Illawarra & 5.423 & 0.167 \\
\hline Number of sectors with lowest MAPE & 4 & 16 \\
\hline \multicolumn{3}{|c|}{} \\
\hline \multicolumn{3}{|c|}{ Mean absolute percentage errors for sectoral employment forecasts 2009-2010 } \\
\hline Integration approach & Coupled & Holistic Embedded \\
\hline Illawarra & 3.756 & 6.459 \\
\hline Number of sectors with lowest MAPE & 18 & 9 \\
\hline
\end{tabular}

The second experiment is a comparison of the impact analysis capabilities of the three integration approaches, namely coupled, holistic embedding and linked, together with the standalone IO analysis. In these experiments, the four different models are applied to estimate the employment impacts on six sectors, arising from a hypothetical increase of AU\$1 million in government expenditure on three sectors, namely retail, education, and health and social services. Table 2 shows the results of the impact analysis of the coupled approach with respect to employment multipliers that it generated during. 
International Symposium for Next Generation Infrastructure October 1-4, 2013, Wollongong, Australia

Table 2. Employment multipliers from the coupled model

\begin{tabular}{|c|c|c|c|c|c|c|c|c|}
\hline \multicolumn{9}{|c|}{ Employment Multipliers } \\
\hline Sector & Initial & First Round & Indust Sup & Consumption $T$ & otal & Elasticity & Type I & Type II \\
\hline Agric, Forestry, Fis & 9.6742 & 1.3721 & 0.4308 & 1.3373 & 12.8145 & 0.4058 & 1.1864 & 1.3246 \\
\hline Mining & 1.5739 & 0.5007 & 0.2371 & 1.069 & 3.3808 & 1.379 & 1.4688 & 2.1481 \\
\hline Food Mfg & 2.1145 & 2.3745 & 0.7137 & 1.5627 & 6.7654 & 0.3369 & 2.4605 & 3.1996 \\
\hline Textiles and Clothin & 4.3976 & 1.4545 & 0.5411 & 2.0068 & 8.3999 & 0.613 & 1.4538 & 1.9101 \\
\hline Wood, Paper and Prin & 3.6445 & 1.1757 & 0.4678 & 1.9583 & 7.2464 & 0.1532 & 1.451 & 1.9883 \\
\hline Petroleum and Coal P & 0.4606 & 0.3787 & 0.1686 & 0.3972 & 1.4051 & 0.4812 & 2.1882 & 3.0505 \\
\hline Chemical Products & 1.1916 & 0.8764 & 0.4061 & 1.2986 & 3.7726 & 1.2891 & 2.0763 & 3.1661 \\
\hline Rubber and Plastic $\mathrm{P}$ & 2.4064 & 0.7241 & 0.3522 & 1.6071 & 5.0899 & 0.4517 & 1.4473 & 2.1151 \\
\hline Non-Metallic Mineral & 1.9205 & 0.9947 & 0.5302 & 1.7749 & 5.2202 & 0.2599 & 1.794 & 2.7182 \\
\hline Basic Metals and Met & 0.6432 & 0.3779 & 0.2301 & 0.6537 & 1.9048 & 2.3119 & 1.9453 & 2.9616 \\
\hline Transport and Other & 2.9011 & 0.5237 & 0.279 & 1.5524 & 5.2562 & 0.8057 & 1.2767 & 1.8118 \\
\hline Other Manufacturing & 6.3864 & 0.5332 & 0.267 & 1.6479 & 8.8345 & 0.9176 & 1.1253 & 1.3833 \\
\hline Electricity, Gas, Wa & 2.6122 & 0.7618 & 0.3605 & 1.55 & 5.2846 & 0.4201 & 1.4297 & 2.023 \\
\hline Construction & 3.4061 & 1.4059 & 0.81 & 1.8938 & 7.5158 & 1.6092 & 1.6506 & 2.2066 \\
\hline Wholesale Trade & 2.9997 & 1.1688 & 0.5568 & 2.2383 & 6.9636 & 0.5854 & 1.5752 & 2.3214 \\
\hline Retail Trade & 9.6509 & 0.9977 & 0.4879 & 2.7701 & 13.9066 & 0.0907 & 1.1539 & 1.441 \\
\hline Repairs & 6.5239 & 0.8949 & 0.4417 & 1.9993 & 9.8599 & 0.4316 & 1.2049 & 1.5113 \\
\hline Accom, Cafes and Res & 7.3278 & 1.0057 & 0.5073 & 2.1093 & 10.9502 & 0.0214 & 1.2065 & 1.4943 \\
\hline Transport and Storag & 4.0713 & 1.1596 & 0.4849 & 2.0872 & 7.8029 & 0.6714 & 1.4039 & 1.9166 \\
\hline Communication Servic & 2.0874 & 1.1542 & 0.5429 & 1.4387 & 5.2232 & 0.4742 & 1.813 & 2.5022 \\
\hline Finance and Insuranc & 1.8253 & 0.5512 & 0.2495 & 2.5001 & 5.1261 & 0.1024 & 1.4387 & 2.8084 \\
\hline Ownership of Dwellin & 0 & 0.4211 & 0.2058 & 0.4296 & 1.0565 & 0.6269 & 0 & 0 \\
\hline Rental, Hiring and R & 2.3494 & 1.1196 & 0.5551 & 2.0441 & 6.0681 & 0.8151 & 1.7128 & 2.5828 \\
\hline Prof, Scientific and & 3.6418 & 1.4701 & 0.7373 & 2.6276 & 8.4767 & 0.7877 & 1.6061 & 2.3276 \\
\hline Administrative Servi & 4.924 & 1.1682 & 0.5394 & 3.1917 & 9.8233 & 0.8078 & 1.3468 & 1.995 \\
\hline Government and Defen & 6.2997 & 0.9367 & 0.4427 & 3.1898 & 10.8688 & 1.621 & 1.219 & 1.7253 \\
\hline Education and Traini ${ }^{*}$ & 9.6676 & 0.5237 & 0.2162 & 3.9038 & 14.3112 & 0.9052 & 1.0765 & 1.4803 \\
\hline Health and Social Se ${ }^{\star *}$ & 11.429 & 0.3985 & 0.1679 & 3.7088 & 15.7042 & 0.8249 & 1.0496 & 1.3741 \\
\hline Cultural and Recreat & 4.812 & 1.2454 & 0.5716 & 2.1111 & 8.7401 & 0.5755 & 1.3776 & 1.8163 \\
\hline Personal and Other $\mathbf{S}^{\star \star \star}$ & 11.9724 & 0.8154 & 0.3702 & 3.0686 & 16.2266 & 0.207 & 1.099 & 1.3553 \\
\hline
\end{tabular}


The first set of findings in the aforementioned experiment pertains to the comparison of the different models. The total estimated impacts generated by IO in each scenario are below 100 thousands and the flow-on effects below 65 thousands. These results are in sharp contrast with the results estimated from the linked approach, with total estimated impacts above 150 thousands and the flow-on effects nearly 90 thousands in all three scenarios. The results of the linked are substantially different also from the other two integrated approaches. In fact the estimate size of the total and flow-on effects of the linked model is the largest of the four models.

A possible reason for relatively large overestimation from the linked approach is the implicit double counting occurrence in modelling the linked approach. This occurs as a result of using IO analysis to estimate disaggregate total impacts caused by the government expenditure increase that are then aggregated and implemented into the econometric modelling to estimate the dynamic adjustments of the increase. Also the use of the Leontief inverse will extend the impacts of final demand change across other disaggregate sectors in the IO analysis. Hence, the linked multiplier interaction is not isolated to certain sectors in which the original change was introduced.

The substantial difference in the estimate results is due to differences in the structure of the employment demand equations across the three approaches. In general, coupled approach specifies sectoral employment as a function of sectoral output and labour productivity. In contrast in the other two approaches, employment is specified in a method similar to regular econometric modelling. Accordingly, the estimate variance in the linked and holistic embedded approaches is more commensurate with the econometric modelling whilst this variance in the coupled approach is in accordance with the detailed sectoral disaggregation of the IO analysis while retaining the dynamics of the econometric model to a higher extent than the other two approaches.

The second set of findings pertains to the importance of the sector with respect to its direct and flow-on effects on employment. By virtue of the competitive advantage of coupled approach, as a result of its exhaustive estimation and its superior accuracy, the sectoral comparison is conducted analysing the results of the coupled approach. As noted on Table 1, the sector which has the highest total impact on sectoral employment is retail trade. A million dollar increase of government expenditure on this sector increases nearly 15 thousands total impacts on employment. Of this 15 thousands total impact, $2.8 \%$ is the increase on the retail trade sector itself, then the highest impact is on transport and storage, which is $1.9 \%$ increase and third highest impact is on professional and scientific sector with $1.6 \%$ increase impact. The second sector resulting the highest impact on other sectors is education sector, with more than 12.5 thousands total impact and third health and social services with slightly more than 12 thousands impacts.

\section{References}

${ }^{1}$ Glickman, N.J., Economic Analysis of Regional Systems: Explorations in Model Building and Policy Analysis, New York, Academic Press, 1977. 
${ }^{2}$ Anselin, L., and Madden, M., "Integrated and Multiregional Approaches in Regional Analysis", New Directions in Regional Analysis: Integrated and Multiregional Approaches, Belhaven, London, pp. 1-26, 1990.

${ }^{3}$ Batey, P.W.J., and Madden, M., Integrated Analysis Of Regional Systems, Pion, London, 1986.

${ }^{4}$ Conway, R., "The Washington Projection and Simulation Model: A Regional Interindustry Econometric Model", International Regional Science Review, Vol. 13, No.1-2, 1990, pp. 141-165. http://dx.doi.org/10.1177/016001769001300110

${ }^{5}$ Isard, W., and Anselin, L., "Integration of Multiregional Models for Policy Analysis", Environment and Planning A, Vol. 14, No. 3, 1982, pp. 359-376. http://dx.doi.org/10.1068/a140359

${ }^{6}$ Moghadam, K., and Ballard, K.P., "Small Area Modelling Of The Industrial Sector (SAMIS): An Integrated Econometric-Inter-Industry Approach", Environment And Planning A, Vol. 20, No. 5, 1998, pp. 655-668. http://dx.doi.org/10.1068/a200655

${ }^{7}$ Rey, S.J., "Integrated Regional Econometric + Input-Output Modelling: Issues and Opportunities”, Papers in Regional Science, Vol. 79, No. 3, 2000, pp. 271-292. http://dx.doi.org/10.1007/PL00013613

${ }^{8}$ Rey, S.J., "The Performance of Alternative Integration Strategies for Combining Regional Econometric and Input-Output Models", International Regional Science Review, Vol. 21, No. 1, 1998, pp. 1-36. http://dx.doi.org/10.1177/016001769802100101

${ }^{9}$ West, G.R., "A Queensland Input-Output Econometric Model: An Overview”, Australian Economic Papers, Vol. 30, No. 57, 1991, pp. 221-40. http://dx.doi.org/10.1111/j.14678454.1991.tb00541.x

${ }^{10}$ West, G.R., and Jackson, R.W., "Input-Output + Econometric and Econometric + InputOutput: Model Differences or Different Models?" Journal of Regional Analysis and Policy, Vol. 28, No. 1, 1998, pp. 33-48.

${ }^{11}$ Lakshmanan, T.R., "Integrated Multiregional Economic Modelling for the USA", Multiregional Economic Modelling: Practice and Prospects, North-Holland, Amsterdam, pp. 171-188, 1982.

${ }^{12}$ Miller, R.E., and Blair, P.D., Input-Output Analysis: Foundations and Extensions, 2nd edition, Cambridge University Press, UK, 2009. http://dx.doi.org/10.1017/CBO9780511626982

${ }^{13}$ Bullard, C., and Sebald, A.V., "Effects of Parametric Uncertainty and Technological Change on Input-Output Model", Review of Economics and Statistics, Vol. 59, No. 1, 1977, pp. 7581. http://dx.doi.org/10.2307/1924906

${ }^{14}$ Israilevich, P.R., Hewings, GJD, Schindler, G.R., and Ramamohan, M., "The Choice Of An Input-Output Table Embedded In Regional Econometric Input-Output Models", Papers In Regional Science, Vol. 75, No. 2, 1996, pp. 103-119. http://dx.doi.org/10.1007/BF02404702

${ }^{15}$ Klein, L.R.,"The Supply side”, American Economic Review, Vol. 68, No. 1, 1978, pp. 1-7.

${ }^{16}$ Coomes, P., Olson, D., and Merchant, J., "Using A Metropolitan-Area Econometric Model To Analyse Economic Development Proposals”, Urban Studies, Vol. 28, 1991, pp. 369-382. http://dx.doi.org/10.1080/00420989120080401

${ }^{17}$ West, G.R., "Comparison Of Input-Output, Input-Output + Econometric and Computable General Equilibrium Impact Models at the Regional Level”, Economic Systems Research, Vol. 7, No. 2, 1995, pp. 209-27. http://dx.doi.org/10.1080/09535319500000021

${ }^{18}$ Stimson et al., Regional Economic Development: Analysis and Planning Strategy, 2nd edition, Springer-Verlag, Berlin Heidelberg, New York, 2006. 
International Symposium for Next Generation Infrastructure October 1-4, 2013, Wollongong, Australia

${ }^{19}$ Langworthy et al. Human Capital and Regional Development: A Skills and Knowledge Based Approach for Economic Development, VDM Verlag Dr. Muller Aktiengesellschaft \& Co. KG, Germany, 2009.

${ }^{20}$ Australian Bureau of Statistics, "NSW State and Regional Indicators (2008), Catalogue 13381", Australian Bureau of Statistics, NSW, 2008.

${ }^{21}$ Australian Bureau of Statistics, "Census of Population and Housing, Time Series Profile (2011), Illawarra, Catalogue 2003.0”, Australian Bureau of Statistics, NSW, 2011.

${ }^{22}$ Australian Bureau of Statistics, "National Regional Profile, Illawarra SD (2011), Catalogue 1379.0.55.001", Australian Bureau of Statistics, NSW, 2011.

${ }^{23}$ Australian Bureau of Statistics, "National Regional Profile (2011), Wollongong, Catalogue 1379.0.55.001”, Australian Bureau of Statistics, NSW, 2011.

${ }^{24}$ Australian Bureau of Statistics, "Census Community Profile Series, Time Series Profile (2007), Illawarra SD, Catalogue 2003.0", Australian Bureau of Statistics, NSW,2007.

${ }^{25}$ Bertuglia, C.S., Leonardi, G., and Wilson, A.G., Urban Dynamics: Designing an Integrated Model, Routledge, London, 1990.

${ }^{26}$ DEEWR, Employment by Industry - Ranked, Labour Force Data, 2012.

${ }^{27}$ Gerking, S.D., "Input-Output as a Simple Econometric Model", Review of Economics and Statistics, Vol. 58, No. 3, 1976, pp. 274-82. http://dx.doi.org/10.2307/1924949

${ }^{28}$ Illawarra Regional Information Service, IRIS website, accessed 28th March 2012, http://www.iris.org.au/, 2008.

${ }^{29}$ Australian Bureau of Statistics, "Census of Population and Housing (2006), Illawarra SD, Catalogue 2068.0”, Australian Bureau of Statistics, NSW, 2006.

${ }^{30}$ Israilevich, P.R, and Mahidhara, R., "Hog Butchers no Longer: 20 Years of Employment Change in Metropolitan Chicago", Economic Perspective, Vol. 15, No. 2, 1991, pp. 13.

${ }^{31}$ Israilevich, P.R, Mahidhara, R, and Hewings, G.J., Centre for Economic Studies, U.S. Census Bureau, Working Papers, 1994.

${ }^{32}$ Motii, B.B., "A Dynamic Integration Approach In Regional Input-Output And Econometric Models", The Review Of Regional Studies, Vol. 35, No. 2, 2005, pp. 139-160.

${ }^{33}$ Schumann, J., "On Some Basic Issues of Input-Output Economics: Technical Structure, Prices, Imputations, Structural Decomposition, Applied General Equilibrium”, Economic Systems Research, Vol. 2, No. 3, 1990, pp. 229-39. http://dx.doi.org/10.1080/09535319000000016

${ }^{34}$ Stevens, B.G., Treyz, D.E., and James, B., "A New Technique For The Construction Of NonSurvey Regional Input-Output Models And Comparison With Two Survey-Based Models", International Regional Science Review, Vol. 8, 1983, pp. 223-228. http://dx.doi.org/10.1177/016001768300800306

${ }^{35}$ Stover, M.E., "A Comparison of Annual and Benchmark Input-Output Tables in Regional Economic Modelling”, The Annals of Regional Science, Vol. 28, 1994, pp. 223-228. http://dx.doi.org/10.1007/BF01581770

${ }^{36}$ West, G.R., "Sensitivity and Key Sector Analysis in Input-Output Models", Australian Economic Papers, Vol. 21, No. 39, 1982, pp. 365-78. http://dx.doi.org/10.1111/j.14678454.1982.tb00397.x

${ }^{37}$ Australian Bureau of Statistics, "House Price Indexes: Eight Capital Cities (2012), Catalogue 6416.0", Australian Bureau of Statistics, NSW, 2012.

${ }^{38}$ Australian Bureau of Statistics, "Regional Population Growth, Catalogue 3218.0", Australian Bureau of Statistics, Australia, 2012. 